\title{
Governmental policy capacity and policy work in a small place: Reflections on perceptions of civil servants in Prince Edward Island, Canada from a practitioner in the field
}

\author{
Bobby Thomas Robert Cameron ${ }^{\mathrm{a} *}$ \\ ${ }^{a}$ Applied Communication, Leadership and Culture Program \\ University of Prince Edward Island, Canada
}

\section{ARTICLE INFORMATION}

\section{ABSTRACT}

\section{Article history:}

Data submission : 20 December 2020

$1^{\text {st }}$ revision: 30 December 2020

Accepted: 30 December 2020

Available online: 30 December 2020

Keywords: policy capacity; government, civil servants, islands; emic; insider research; qualitative research

\begin{abstract}
The body of public administration literature is missing contributions from practitioners in the field. Emic or insider-led studies of public administration can act as powerful mechanisms to generate new knowledge. This article studies the relationship between place, perceptions and policy work by drawing on the author's own public administration experience and interviews with civil servants. The results show that societal factors such as political culture and reduced anonymity associated with small place create challenges when developing public policy. However, expedited public engagement and problem identification were perceived by civil servants to be enhanced by a small context. This means that small place can be both limiting and beneficial for high levels of policy capacity. Overall, this article finds that geospatial factors such as smallness impact perceptions of policy work and capacity. Furthermore, this article finds that insider-led studies of public administration can indeed make important and unique contributions to the body of literature and are therefore deserving of more serious methodological consideration.
\end{abstract}

2020 FIA UB. All rights reserved.

\section{Introduction}

In the Journal of Public Administration Studies, Said, et al. (2019) discussed how the challenges associated with the geographical conditions of the islands of Sumenep Regency, Indonesia resulted in the need for increased government capacity. Taking a "qualitative stance" when examining public administration processes and uncovering the "discursive and material elements" of public sector services is important for generating knowledge (Bjerge, et al., 2018, p. 51). Heeding the observation of Bjerge, et al. (2018), this article presents the results of a qualitative study of provincial government policy capacity in the Canadian province of Prince Edward Island (PEI).

There exists a small collection of work which has focused on the policy capacity of sub-national provincial jurisdictions in Canada (e.g., Rasmussen, 1999; Howlett, 2009; Inwood, et al., 2011; Bernier and Howlett, 2012;
Bédard, 2015). Many of these studies use interviews and surveys with provincial public administrators and attempt to uncover perceptions of governmental policy capacity. To the best of my knowledge, no studies exist where a public administration practitioner has acted as a formal researcher and completed a study of policy capacity in their own place of work. This article fills this gap based on an analysis of interviews with civil servants. Furthermore, studies of policy capacity in small island jurisdictions are scarce.

Qualitative emic (insider) research in public administration can be a powerful mechanism to uncover tensions, successes and failures in day-to-day public administration practice. My background as a governmental policy analyst, manager and now a director in the Canadian province of Prince Edward Island provides me with a unique vantage point to study policy capacity in this province. I have been involved in 
the development and evaluation of public policies and programs, the recruitment, hiring and training of policy staff and interdepartmental, multi-sectoral and federalprovincial-territorial policy initiatives. Unfortunately, practitioner-based experience such as this is often relegated (in research terms) as less-than rigorous, inferior to other "hard" forms of evidence, or considered as purely anecdotal. This is somewhat ironic, given the long-standing persistence of public administration academics to bridge the theory-practice divide, more meaningfully include practitioners in their research agendas, and complete research that has real-world implications for governments.

The study presented in this article, however, intentionally drew on my own experiences. The purpose of doing so was not to just simply identify research questions that would be useful to practitioners in the field, but to more seriously act as connective tissue to triangulate results, tie together findings and present recommendations in such a way that would make sense to practitioners.

Inside, insider or emic research is often constructivist-interpretive in nature given the researcher's already existing familiarity with the research site (Morey \& Luthans, 1985; Brannick \& Coghlan, 2007; Galea, 2009, p. 4; Teusner, 2016, pp. 86-87). The terms phoneemic (inside) and phonetic (outside) were introduced by anthropologist Kenneth Pike in the 1950s and have since been widely employed by researchers, to various degrees (Morey \& Luthans, 1985 , p. 29). There is often a position explicated through insider-research studies that practitionerresearchers' knowledge of the context of the organization, and their status as an actor in the setting, is implicated in the construction of reality (Galea, 2009, p. 4; Morey \& Luthans, 1985; Teusner, 2016, pp. 86-87). In addition to interviews with my colleagues, the study in this article was guided by my own experiences: These experiences led me towards important sources of information, shaped how I asked questions to uncover truths and led me to interpret and present findings in a way that is hopefully meaningful to both academics and public administrators.

\section{Theory}

\subsection{Perceptions in public administration research}

The study of perceptions in public administration finds its academic home in the broader field of narrative inquiry, which "in public administration ... often focuses on the stories that people in public institutions tell about their work, illuminating diverse dimensions of public institutions and their administrative and policy problems" (Dodge et al., 2005, p.286). Studies have argued that understanding public administrators' perceptions of various administrative phenomenon is important to improve service delivery by identifying points where administrators' perceptions do not align with one another (Emery et al., 2008, pp.312-313), understand how or why new technologies implemented in government may succeed or fail (Christensen and Lægreid 2010, p.8), understand the value-related components of the policy process (Lahat, 2011, p.147) and identify areas where capacity development is needed (Wenene et al., 2015, p.174).

Furthermore, policy work is inherently a valueladen, interpretive and socially-constructive process. Through the development, implementation, and evaluation of public policy, people seek to understand and shape practices to govern societies and control political processes (Colebatch, et al., Eds., 2010, p. 29; Williams, 2010, p. 201). Qualitative approaches are therefore a good fit for research that seeks to understand policy workers' lived experiences and perceptions. I argue that such approaches allow us to deepen and complicate existing knowledge of policy work in practice.

\subsection{Prince Edward Island and sub-national island jurisdictions}

Globally, there are over 100 territories that are classified as a sub-national island jurisdiction (SNIJ) (Baldacchino 2010, p.6). A considerable amount of literature exists on the cultural, developmental and economic reality of small island countries and SNIJs (e.g., Baldacchino \& Stuart Ed.s, 2008; Baldacchino Ed., 2015; Baldacchino Ed., 2018). Yet, literature on governmental policy capacity in this type of jurisdiction is lacking. This means that not only is there a gap in knowledge about SNIJs, but also about the interplay between small size and policy capacity.

Furthermore, the positivist thrust to most policy capacity literature, and its focus on the analytical capacity and training of the individual civil servant, means that knowledge about policy capacity lacks theory-based studies of organizational and systemic factors and context. The academic focus on the analytical capacity and training of civil servants assumes that solely the number of highly trained policy workers who are engaged in analysis is an accurate assessment of policy capacity.

Prince Edward Island is Canada's smallest province by population and size (approximately 157,000 residents). The size of the PEI civil service is approximately 2,100 . In PEI, there is often a reduction in boundaries between government and citizens, in part because PEI is the most densely populated province in the country, but also because of long-standing expectations of citizens to have instant access to senior level decision-makers. Often, this results in a blurring of 
private, public and political life. From a researcher's perspective, a jurisdiction that is sub-national, small, relatively remote and an island makes an interesting case study for the exploration of policy work and policy capacity.

Sub-national policy capacity in Canada can be conceptualized as a distinct field of empirical study, and it recognizes that provincial governments such as PEI collectively provide almost two-thirds of all government services (McArthur, 2007., p. 238). As noted by researchers studying provincial governments in Canada, provincial policymaking covers many important aspects of social, economic and political life (Howlett, 2009, p. 51; Atkinson et al., 2013, p. 26; Sá and Hamlin, 2015, p. 469; Howlett and Wellstead, 2017, p. 88). Yet in some cases, sub-national governments lack adequate resources to develop successful public policies (Haddow et al., 2006, p. 327).

A small community of public administration researchers, political scientists and historians have made important historical and contemporary contributions to knowledge on public administration in PEI. Buker's (2005, p. 130) analysis of the executive administration style of PEI's public administration is often cited to show how "the executive [in PEI's public administration] reflects a more seamless administrative relationship to its elites and citizenry than in other provinces, and, consequently, its style is far more determined by socio-cultural factors than by structural and institutional factors." Buker (2005) calls this executive the non-competing single elite, summarized by Simpson (2007, p. 35) as, "a permanent cadre of partisan brokers whose influence generally outlives elections, but whose fortunes are tied to election outcomes."

Austerity and a lack of policy training is argued to have negatively impacted the ability of government in PEI to develop effective public policy (McKenna, 2014; Conrad, 2018). The global economic crisis of 2008 was experienced by the Government of PEI in the face of a "languishing fiscal performance" (Conrad, 2018, p. 245). The economic crash placed additional pressures on PEI's public service, which was already considered to be austere (Conrad, 2018, p. 270). Leading up to the crisis, government implemented cost-cutting measures and the elimination of management and administrative positions (Conrad, 2018, p. 255, 256). The combination of the former, according to Conrad (2018, p. 265), "had seriously eroded the ability of government staff to pursue strategic policy development." At the same time, deputy ministers in PEI have been found to lack knowledge related to government processes, legislative processes and operational leadership which negatively impacts the ability to develop strategic public policy (McKenna, 2014, p. 82, pp. 94-95).
The study presented in this article is therefore set in a context of a SNIJ and existing academic discourses that have pointed to challenges with policy capacity in this jurisdiction.

\section{Research Method}

The analysis in this article relies on the qualitative data from a mixed-methods PhD study (Cameron, 2019). For the qualitative component of the study, semi-structured interviews were conducted with deputy ministers (DM) from across the Government of PEI (eleven total, 92 per cent) and interviews were completed with managers (M) and directors (D) at one department responsible for natural resources (twenty-one total, 95 per cent). To protect the privacy of individuals involved in the study, I have chosen not to disclose detailed demographic information about the respondents. The sample of interviewees included a range of genders, ages, educational backgrounds and work experiences. The sample was therefore inclusive of a diversity of perspectives on policy work and capacity in government. After receiving ethics approval from Ryerson University's Research Ethics Board, interviews were completed in early 2018.

To ensure the credibility of the study, I fully described my basic assumptions and theoretical frameworks (Musson, 2004, p.35), maintained notes to record everyday assumptions and biases that emerged throughout the research process (Teusner, 2016, p.89, p.93; 2019) and was conscious of maintaining the study's qualitative-interpretive theoretical drive (Morse, et al., 2006). I also linked and triangulated data from the qualitative and quantitative phases to develop findings (Hesse-Biber, 2010, p.109), which I shared with respondents to ensure the accuracy of my interpretations (Kaiser, 2009, p.1638). Furthermore, care was taken during interviews not to assume an explicit or overt normative position towards policy capacity or any other concept under study (Inwood et al., 2011, p.418). I ensured that my tactic knowledge of the Government of PEI did not impact the confirmability or dependability of my findings by probing interviewees to obtain clarity for those statements that were only familiar to me as an insider but may not otherwise be clear to an outsider (Teusner, 2016, p.91).

\section{Results}

\subsection{Policy capacity}

Policy capacity takes into consideration more than the analytical capacity of policy workers to complete research to support policy-relevant decision-making. In theory, to improve the effectiveness of public policy, strong policy capacity requires analytical, operational 
and political capacities at the micro (individual), meso (organizational), and macro (systemic) levels (Wu et al., 2018). According to Wu, Ramesh and Howlett (2018, p.3) conceptualizing policy capacity this way is "sufficiently broad enough to encompass all aspects of policy capacity." While each level is "governed by different considerations" (and can therefore be studied separately), similar skills and competences are often applied at all three levels (Wu et al., 2018, p.5).

Considering policy capacity at the systemic level requires "looking[ing] beyond" government (Wu et al., 2018, p.4). This does not mean that what has been called 'within puts' - the effects on policy or the organization of policy that originate from within a bureaucracy - are not important. Rather, as described by $\mathrm{Wu}$, Ramesh and Howlett $(2015,2018)$, systemic-level analysis of policy capacity recognizes that the policy environment and society "affects the ability of a government to exercise its political skills in the course of policy-making" ( $\mathrm{Wu}$ et al., 2015, p.272). The policy environment includes factors that are often beyond the control of government, and consider the culture, values, epistemic communities and other organizations present in the setting (see Lah, 2017). To understand policy capacity in the Government of PEI therefore requires understanding the policy environment and the context of policymaking in this jurisdiction. Following this line of thinking, one questions the extent to which being a small SNIJ may affect government's policy capacity and public administrators' perceptions of the former. This article addresses this point based on the perceptions of practitioners in the Government of PEI.

\subsection{Results: provincial government policy capacity in PEI}

To contextualize the setting for a study of the Government of PEI's policy capacity, participants were asked to describe if they thought that policymaking in PEI was in any way unique from other jurisdictions in Canada. Respondents drew on ecological, cultural, economic, and political features external to the Government of PEI. In other words, participants described the system or macro context in which government is creating public policy. As such, the relationship between place and perceptions of policy capacity and policy work matters. Based on participants' responses to this question, six themes of response types were constructed: 1) the perceived uniqueness of PEI and its culture, 2) geography and environment 3) reduced anonymity of policymakers from the public, 4) reduced physical distance between policymakers and the public, 5) unique opportunities for policy capacity and 6) unique challenges.

\subsection{Discourses of uniqueness and exceptionalism}

The idea that culture in PEI is different from the rest of Canada was a theme in participants' responses. Participants reiterated to me that, "I think we are unique" (D5), "PEI is unique" (M6), "PEI is a unique place" (M11), and "I...think we are probably very unique" (M13). PEI exceptionalism was most apparent when participants made comparisons of how they perceived the character of public policy in PEI to that in other provinces. Therefore, when it comes to policy workers' perceptions of policy work in PEI, difference is a driving force behind exceptionalism. By way of making comparisons of PEI with other provinces, participants thus also shed light on how they understand policymaking in other jurisdictions. More specifically, participants believed that there is a uniqueness and exceptionality associated with culture in PEI. Cultural uniqueness was attributed to small size, small communities and unique attitudes towards political participation that increase the propensity of the public to become involved in policymaking. Participants also expressed cultural exceptionalism by alluding to an inherent "island way of life" (M11) in this jurisdiction, which is different from the rest of Canada.

The character of public policy in PEI is constructed in part by the ecological reality of being a small jurisdiction surrounded by water and the resulting effect this has on policymaking (as well as daily life). The fact that the province is surrounded by water prompted a director to comment that PEI, therefore, had unique policy challenges when it comes to transportation and the environment. The director told me that, "[Since PEI is] separated from the mainland by water, ... there are ... transportation [issues], and environmental issues that are different from some of the other provinces" (D5). Having only one major airport, one bridge and one ferry system to transport people to and from the island can further a feeling of being isolated and cut-off from the rest of the country. A director shed light on this idea when they said that "environmental issues ... are different from other provinces" (D8). Particularly during stormy seasons, the environment can pose challenges for the supply of goods with the closure of transportation routes, as well as the migration of people to and from the province. This reality may not necessarily be experienced the same way in other jurisdictions. Furthermore, in terms of PEI's ecological environment, due to being small in geographic size and surrounded by water, development was perceived to be inherently more limited than other jurisdictions. A deputy minister said to me, "We only have so much land, where we have so much water. There's only so much we can develop" (DM28). 
Studies of public administration in PEI have tangentially pointed to a lack of anonymity between policymakers and the public (see Srebrnik 2004, pp. 334 - 335; Baldacchino, 2005, p. 36; Connor, 2008, pp.4849). The assumption is that, when compared to larger mainland jurisdictions, small islands offer less or reduced anonymity between residents. "Everybody know[s] everybody else's business" (M6) a manager told me. Essentially, I was told that part of the reason why policy was different in PEI from other provinces was because of the lack of anonymity of PEI public servants. Referring to the social network in PEI, a deputy minister said, "We are pretty connected. And of course, people know who people are here in a way that they wouldn't know in a larger jurisdiction. Even if...contact was made [with a member of the public] in a larger jurisdiction, [public servants] wouldn't have any context on who the person is" (DM23). The lack of anonymity between policymakers and the public, for a director, meant that emotions often become involved in the policymaking process. This director said to me, "because with the emotional piece, because we're so close, it's not just like people can be angry and then they go away. You see [those impacted by public policy] and you're around them" (D8).

The lack of anonymity is likely compounded by the fact that, not unlike life in small towns located on the mainland, residents are regularly encounter one another outside of formal settings; at the grocery store, social events, and during other aspects of daily life. The reduced physical distance between policymakers and the public contributes to reducing the anonymity and autonomy between these policy actors. "Our politicians ... definitely get people on their doorstep. There is much more influence from the general public I think in [PEI] than in a bigger centre" (D5).

\subsection{Discourses of policy work benefits and constraints in a small place}

Some participants in the study found that PEI's culture and small scale, described above, as being directly beneficial in terms of policy effectiveness and innovation. A manager told me how they believed that "it's lower-cost [for government to]...roll out [policy]. It's not like...we're...dealing with millions of people. I think that works better for PEI" (M19). This manager went on to explain that, "[the Government of PEI is] able to get a lot of things done because we're so small. I know...[that] other jurisdictions [are] jealous of us because we have such a small population" (M19). As such, the small size of PEI (in terms of population and geography) contributes to a perception that policy capacity can sometimes be enhanced in this jurisdiction because the cost of policy implementation requires, relative to other jurisdictions, fewer resources.
Small size is a systemic factor that is perceived to contribute to policy innovation in PEI. Participants expressed this idea in terms of PEI's ability to act as a case study to test out innovative policy ideas, as well as the Government of PEI's ability to easily identify new solutions (see also Buker, 2005, p.124). A director surmised that, "Because we are an island and we are a small province ...we can actually be, the guinea pig!" (D4). Another director explained how they "think the solution is perhaps better found in a small jurisdiction than a large jurisdiction because ... we possibly can make some inroads in stopping some things" (D8). Discovering innovative solutions and, as such, making "inroads in stopping some things" (i.e., problems) before they escalate, is perhaps facilitated in PEI by the lack of autonomy between policymakers and the public. A manager shared how they often know what "the word on the street" (M16) is because, "You're going around, and you start hearing something [from clients] and you bring it back [to the Department] and say, '... I've been hearing this: I think ... we have to keep our eyes on this" (M16). In this case, limited autonomy and the close relationships between policymakers and the public in PEI may result in more opportunities for collaboration and the identification of innovation solutions by drawing a policymaker's attention to things which they may have not yet considered. This is an important factor to consider in future studies of policy capacity in small places.

In addition to participants sharing how policy opportunities are associated with smallness, there were also strong arguments pointing to unique challenges. Specifically, issues with making difficult policy decisions, difficulties in remaining objective, political influence and interference and problems associated with rapid change. Yet, as the results below show, in some cases, what is considered a challenge is, at the same time, considered an opportunity.

Participants communicated that smallness presents real challenges for policymaking, in terms of making difficult policy decisions. Participants shared that the reduced autonomy or physical distance between policymakers and the public in PEI meant that sometimes, in practice, there is a hesitancy to implement difficult changes because of the personal relationships that exist between government and the public. The idea that lack of anonymity and autonomy intersect and make difficult decisions more challenging to implement was reiterated by a manager who said, "You make a policy decision here [and then] you may be walking down the street [and] see the person whom you know the policy decision is affecting. And I think that's probably not seen in any other jurisdiction" (M13).

Furthermore, lack of anonymity is "not always positive" (DM23). Removing emotions from 
policymaking can be challenging when public servants or politicians have to make difficult decisions, and they personally know the individuals who may be negatively impacted (see Cairney et al. 2016, where they discuss the interplay between emotions and evidence in policymaking). A deputy minister made the connection between lack of anonymity and emotions: "I don't want to say [that it's]...politics, but it's the emotion. Because it's so small, it's easy for you to get focused on a particular situation" (DM25).

Being a small island was also associated with challenging public servants to remain objective throughout the policy process. A lack of anonymity and autonomy was perceived as "a definite challenge" (M13) because "it potentially influences your objectivity" (M13). Furthermore, as expressed by another manager, "I think there's probably more...public [and] political influence...on the island than you would get in most jurisdictions, given our size and how small...we are and [because] everybody knows everybody" (M18). For this manager, political influence was inherently a part of policymaking in PEI. This manager went on to state, "people are always trying to push [an agenda] and because we're so small, it's easy to do that, right?" (M18). This reality results in a situation where discourses promoting scientific and evidencebased forms of policy development are challenged in day-to-day public administration practice.

While participants pointed to examples of how they perceived system-level factors in PEI as supporting public engagement, they also noted that there can be challenges. A deputy minister pointed to the idea of how, in PEI, political interference and influence can intersect with limited autonomy during the public engagement process: "Because we are so small, and because so many people have access to politicians, then that often usurps the true and formal consultation process. I have seen where a planned-out consultation process was usurped where people went directly to a minister. There is such a small group who have influence over someone in policy" (DM21). This means that formal stakeholder engagement activities can be made obsolete when political interference and influence intersects with limited autonomy. The former statement from a deputy minister directs attention to the idea that limited autonomy between policymakers and the public - and the easy access the public has to politicians - while supporting forms of direct democracy, also poses challenges for truly inclusive and representative forms of stakeholder engagement.

The smallness of PEI, and the limited autonomy and anonymity between policymakers and the public, was also perceived to support the cultivation of a policy environment that was susceptible to rapid change (see also Baldacchino 2002, pp.356-357 for a discussion of rapid change in small island territories). The ease of access that the public has to policymakers, and particularly politicians, means that new ideas can quickly make their way into the public service. While the rapid introduction of new ideas may be important for innovation, it also can cultivate a policy environment in PEI's public service that may feel unstable and sometimes chaotic. A manager alluded to this idea when they said, "On the negative side...it can change. Because... policymaking [in] PEI [means that] a good strong wind can change [things]" (M6).

Furthermore, while the character of public policy in PEI is associated with an ability for relationships between policymakers and the public to form quickly which is important for strong policy capacity - these relationships are also susceptible to rapid change. When discussing the Government of PEI's relationship with stakeholders, a deputy minister quipped, "You can also burn those bridges a lot faster, too. Your margins for error are very narrow." Since the potential to "burn bridges" with stakeholders is perceived to be greater PEI, where there is reduced autonomy between policymakers and the public, rapid change is, therefore, both a benefit and challenge in small jurisdictions.

\section{Discussion and conclusion}

This article has looked at the interplay between a densely populated small place and the impact this has on civil servants' perceptions of policy capacity. In doing so, it has brought forward a discussion of the interplay between public administration and society in PEI and also the utility of being both researcher and practitioner.

It is perhaps the close proximity of policymakers and the public that has the most profound impact on policy capacity and policy work in this province. Connor (2008) argued that,

"PEI was not able to develop an internal government structure beyond the personal. This meant that, rather than technical expertise, PEI bureaucrats and politicians gained proficiency at linking personal relationships to policy goals and vice versa. In PEI, ministers of the crown may get personally involved in issues in ways not practical or expected in any other province." (pp. 48-49)

While policy capacity theory would reason that close and personal relationships may challenge the ability for evidence to trump values and emotions, smallness also presents an opportunity for increased policy capacity: Public engagement and participatory policymaking in PEI is enhanced by the close connection that government has to citizens. Government can understand problems early on and in some cases, 
react more quickly. The potential benefits of small scale is therefore an element of policy capacity that needs to be considered for future studies of governmental policymaking abilities.

My interpretation of findings is conscious of the risk of conflating islandness and small scale, as each are often "intertwined in theory and practice" (Baldacchino and Veenendaal, 2018, p.340; see also Warrington and Milne, 2018, p.174). Participants indeed conflated smallness and islandness, so much so that the two were considered by civil servants to be one and the same. Therefore, this points to the finding that islandness is, as argued by Anckar (2006), an important factor for political scientists and policy scholars to include in their analysis when attempting to understand the institutional choices made by an organization in an island jurisdiction. The results also allow the present study to extend this argument, and posit that islandness - even if only perceived by civil servants to impact administrative culture - is an important factor to consider when attempting to understand policy capacity and policy work in island jurisdictions. Islandness, and the islandness of policy work, is more complicated than geographic small scale or size alone, because islandness takes into consideration the complexities of social construction, identity, culture, history, ecology, and sense of place. In the future, more research is needed to understand the impact islandness has on governmental policy capacity as opposed to small scale.

Culture in PEI has been shaped by such factors as an historically European demographic profile (Scottish, Irish, and English), politics, a tourism-focused pastoral identity (MacDonald, 2011), the historical legacy of a Catholic system of social order (MacDonald, 2003), and the province's connection to land and water (MacDonald et al., 2016). The water surrounding PEI intensifies a sense of isolation among Islanders and a feeling that life is different on PEI when compared to the mainland (MacDonald et al., 2016, pp.22-23). Even with less farmers now than there were in the past, agriculture continues to occupy, in varying degrees, the cultural imagination of how Islanders view who they were in the past and present.

The results in this article build on these types of cultural discourses: In PEI, the lines between the public, politicians, and government are often blurred, resulting in a highly personal and personality-related culture towards governance (Buker, 2005, pp. 111-112). McKenna (2015, p.55) views the generally conservative and insular nature of PEI politics and culture as having a distinct impact on public policy in this jurisdiction. The smallness of PEI and propensity of residents to seek ways to be involved in the political process results in a situation where local interest groups, the media, and the general public can "shape public policy decisions" relatively easily (McKenna, 2015, p.53, p.55). The political and cultural environment within which civil servants in small places develop and implement public policy has an impact on the character of policy work and limits of policy capacity.

While the non-comparative approach of this study does not allow for empirical comparisons with other jurisdictions to be drawn, island studies scholarship on islandness (e.g., Gill, 1994; Hay, 2006; Vannini and Taggart, 2013; Bates et al., 2019), and the results presented here, supports the recommendation that researchers interested in policy capacity in other small island jurisdictions should consider how islandness, as constructed in the island jurisdiction under study, interacts with government's ability to develop public policy. As noted by Bates et al. (2019: 172), "islandness [adds] nuance to the contours of human experience." In the case of the present study, public administrators' discussions of being an island jurisdiction discursively intersected with how they understood policy capacity: Participants perceived islandness to shape the way in which policy work was conducted, and also pose unique challenges and unique opportunities for policy capacity. In the future, governments in small SNIJs should be compared to see whether it is physical or conceptual smallness, islandness or both that is more impactful in shaping perceptions of policy work and capacity.

Finally, the result showing that the concept of policy capacity was not fully understood by practitioners means that there is a gap in theory and practice. Academic theories showing the importance of strong analytical, operational, and political factors at the individual, organizational and systemic level is not a way of thinking that is necessarily useful to practitioners. This does not mean that civil servants do not have an opinion of what factors may be required for effective public policy. Rather, this result points to the need for researchers to develop policy capacity models and frameworks inductively, beginning with developing concepts using the language and ideas accepted practitioners. Policy capacity frameworks built on experiential practitioner knowledge will help to develop a common epistemic community around policy capacity, which will then improve assessments of governmental policy capabilities, increase the likelihood of concepts being adopted in the field and ultimately improve the likelihood that public policies are effective. Gaining access to the experience-based knowledge of practitioners is significantly improved when the researcher is a member of the organization under study. 


\section{References}

Anckar, Dag. 2006. "Islandness or smallness? A comparative look at political institutions in small island states". Island Studies Journal 1 (1): 43-54.

Atkinson, Michael, Daniel Béland, Gregory P. Marchildon, Kathleen McNutt, Peter W.B. Phillips, and Ken Rasmussen. 2013. Governance and Public Policy in Canada: A View from the Provinces. Toronto, Ontario: University of Toronto Press.

Baldacchino, Godfrey. 2002. "Jurisdictional selfreliance for small island territories: Considering the partition of Cyprus." The Round Table: The Commonwealth Journal of International Affairs 91 (365): 349-360. DOI: https://doi.org/10.1080/0035853022000010326

Baldacchino, Godfrey. 2005. "The contribution of 'social capital' to economic growth: Lessons from island jurisdictions." The Round Table 94 (1): 3146.

DOI:

https://doi.org/10.1080/00358530500033075

Baldacchino, Godfrey (Ed.). 2015. Entrepreneurship in Small Island States and Territories. New York: Routledge.

Baldacchino, Godfrey (Ed.). 2018. The Routledge International Handbook of Island Studies: A World of Islands. New York: Routledge.

Baldacchino, Godfrey and Kathleen Stuart (Eds.). 2008. Pulling Strings: Policy Insights for Prince Edward Island from other Sub-National Island Jurisdictions. Charlottetown: Island Studies Press.

Baldacchino, Godfrey and Wouter Veenendaal. 2018. "Society and community." In The Routledge Handbook of Island Studies: A World of Islands, edited by Godfrey Baldacchino. New York, New York: Routledge.

Bates, Laura, Tara Coleman, Janine Wiles, and Robin Kearns. 2019. "Older residents' experiences of islandness, identity and precarity: Ageing on Waiheke Island." Island Studies Journal 14 (2), 171-192. DOI: https://doi.org/10.24043/isj.92

Bédard, Pierre-Olivier. 2015. "The mobilization of scientific evidence by public policy analysts: Path analysis and predicted probabilities." Sage Open 5 (3): 1-15. DOI: https://doi.org/10.1177/2158244015604193

Bernier, Luc and Michael Howlett. 2012. "The policy analytical capacity of the government of Quebec: Results from a survey of officials." Canadian Political Science Review 6 (2-3): 281-285. DOI: https://doi.org/10.3138/9781442668034-007

Bjerge, Bagga, Tobias Eule, and Kasper Elmholdt. 2018. "Researching organisational imbrications and interstices: A qualitative gaze on how mundane public administration works." Qualitative Studies 5
(2),

49-56.

DOI:

https://doi.org/10.7146/qs.v5i2.111314

Brannick, Teresa and David Coghlan. 2007. "In defense of being 'native': The case for insider academic research." Organizational Research Methods 10 (1): 59-74.

DOI:

https://doi.org/10.1177/1094428106289253

Buker, Peter. 2005. "The executive administrative style in Prince Edward Island: Managerial and spoils of politics." In Executive Styles in Canada: Cabinet Structures and Leadership Practices in Canadian Government, edited by Luc Bernier, Keith Brownsey, and Michael Howlett. Toronto, Ontario: University of Toronto Press.

Cairney, Paul, Kathryn Oliver, and Adam Wellsetad. 2016. "To bridge the divide between evidence and policy: Reduce ambiguity as much as uncertainty." Public Administration Review 76 (3): 399-402. DOI: https://doi.org/10.1111/puar.12555

Cameron, B. (2019). "Perceptions of policy capacity: A case study of the Prince Edward Island civil service using theory and practice" (Doctoral Dissertation, Ryerson University, Toronto, ON). Available from the Ryerson Library Digital Repository, https://library.ryerson.ca/info/collections-2/digitalcommons/

Christensen, Tom and Per Lægreid. 2010. "Civil servants' perceptions regarding ICT use in Norwegian central government." Journal of Information Technology \& Politics 7 (1): 3-21. DOI: https://doi.org/10.1080/19331680903080603

Connor, Hans. 2008. "The capacity for sub-national island jurisdictions to increase autonomy: The example of Prince Edward Island." In Pulling Strings: Policy Insights for Prince Edward Island from other Sub-National Island Jurisdictions, edited by Godfrey Baldacchino and Kathleen Stuart. Charlottetown, PE: Island Studies Press.

Conrad, Patricia. 2018. "Austerity in the garden province of Prince Edward Island." In The Public Sector in an Age of Austerity: Perspectives from Canada's Provinces and Territories, edited by Bryan M. Evans and Carlo Fanelli. Montreal, Quebec \& Kingston, Ontario: McGill-Queen's University Press.

Dodge, Jennifer, Sonia M. Ospina, and Erica Foldy. 2005. "Integrating rigor and relevance in public administration scholarship: The contribution of narrative inquiry." Public Administration Review 65 (3): 286-300. DOI: https://doi.org/10.1111/j.15406210.2005.00454.x

Emery, Yves, Carole Wyser, Noemi Martin, and Joelle Sanchez. 2008. "Swiss public servants' perceptions of performance in a fast-changing environment." 
International Review of Administrative Sciences 74 (2): 307-323. DOI: https://doi.org/10.1177/0020852308089906

Galea, Annabel. 2009. Breaking the barriers of insider research in occupational health and safety. Journal of Health \& Safety, Research \& Practice, 1 (1): 312.

Gill, Peter. 1994. "Island psyche: Fieldnotes from an Irish island." The Irish Journal of Psychology 15 (23): 276-287. DOI: https://doi.org/10.1080/03033910.1994.10558011

Haddow, Rodney, Steffen G. Schneider, and Thomas R. Klassen. 2006. "Can decentralization alleviate labour market dysfunctions in marginal jurisdictions? Active labour market policies in Nova Scotia and Saxony-Anhalt." Canadian Public Policy 32 (3): 317-337. DOI: https://doi.org/10.2307/4128741

Hay, Pete. 2006. "A phenomenology of islands." Island Studies Journal 1 (1): 19-42.

Hesse-Biber, Sharlene. 2010. Mixed Methods Research: Merging Theory with Practice. New York, New York: The Guilford Press.

Howlett, Michael. 2009. "A profile of B.C. provincial policy analysts: Troubleshooters or planners?" Canadian Political Science Review 3 (3): 50-68.

------ and Adam Wellstead. 2017. "Policy analysis in the bureaucracy revisited: The nature of professional policy work in contemporary government." In Policy Work in Canada: Professional Practices and Analytical Capacities, edited by Michael Howlett, Adam Wellstead, and Jonathan Craft. Toronto, Ontario: University of Toronto Press.

Inwood, Gregory, Carolyn Johns, and Patricia O'Reilly. 2011. Intergovernmental Policy Capacity in Canada: Inside the Worlds of Finance, Environment, Trade, and Health. Montreal, Quebec \& Kingston, Ontario: McGill-Queen's University Press.

Kaiser, Karen. 2009. "Protecting respondent confidentiality in qualitative research." Qualitative Health Research 19 (11): 1632-1641. DOI: https://doi.org/10.1177/1049732309350879

Lah, Oliver. 2017. "Factors of change: The influence of policy environment factors on climate change mitigation strategies in the transport sector." Transportation Research Procedia 25: 3495-3510. DOI: https://doi.org/10.20944/preprints201704.0004.v1

Lahat, Lihi. 2011. "How can leaders' perceptions guide policy analysis in an era of governance?" Policy $\begin{array}{llll}\text { Sciences } & 44 & \text { (2): } 135-155 . & \text { DOI: }\end{array}$ https://doi.org/10.1007/s11077-010-9119-x

MacDonald, Edward. 2011. "A landscape . . . with figures: Tourism and environment on Prince Edward Island." Acadiensis 40 (1): 70-85.

MacDonald, Edward, Joshua MacFadyen and Irené Novaczek. 2016. Time and a Place: An Environmental History of Prince Edward Island. Montreal \& Kingston, Ontario: McGill-Queen's University Press and Charlottetown, PE: Island Studies Press.

MacDonald, Heidi. 2003. "Developing a strong Roman Catholic social order in late nineteenth-century Prince Edward Island." Historical Studies 69: 34-51.

McArthur, Doug. 2007. "Policy analysis in provincial governments in Canada: From PPBS to network management." In Policy Analysis in Canada: The State of the Art, edited by Laurent Dobuzinskis, Michael Howlett, and David Laycock. Toronto, Ontario: University of Toronto Press.

Morey, Nancy and Luthans, Fred. 1984. An emic perspective and ethnoscience methods for organizational research. Academy of Management $\begin{array}{llll}\text { Review, } & 9 & \text { (1): } & \text { 27-36. }\end{array}$ https://doi.org/10.2307/258229

Morse, Janice, Linda Niehaus, and Ruth Wolfe. 2006. "Principles and procedures for maintaining validity for mixed-method design." In Qualitative Methods in Research and Public Health: Aging and Other Special Populations, edited by Leslie Curry, Renee Shield and Terrie Wetle. Washington, DC: American Public Health Association.

------, Linda Niehaus, Ruth Wolfe, and Seanne Wilkins. 2006. "The role of the theoretical drive in maintaining validity in mixed-method research." Qualitative Research in Psychology 3 (4): 279-291.

Musson, Gill. 2004. "Life histories." In Essential Guide to Qualitative Methods in Organizational Research, edited by Catherine Cassell and Gillian Symon. Thousand Oaks, California: SAGE Publications Inc.

Rasmussen, Ken. 1999. "Policy capacity in Saskatchewan: Strengthening the equilibrium." Canadian Public Administration 42 (3): 331-348. DOI: $\quad$ https://doi.org/10.1111/j.17547121.1999.tb01554.x

Sá, Creso and Daniel Hamlin. 2015. "Research use capacity in provincial governments." Canadian Public Administration 58 (3): 468-486. DOI: https://doi.org/10.1111/capa.12125

Said, Moh, Bambang Supriyono, M. R. Khairul Muluk, and Bambang Haryono. 2019. "Equitable distribution of community welfare: Alignment of local government capacvity and territorial challenges." Journal of Public Administration 
$\begin{array}{llll}\text { Studies } \quad 4 & (2): & 85-90 . & \text { DOI: }\end{array}$ http://dx.doi.org/10.21776/ub.jpas.2019.004.02.7

Simpson, Andrea M. 2007. "Political culture and policy practice in Prince Edward Island." Optimum Online 37 (1): $35-42$.

Srebrnik, Henry. 2004. "Small island nations and democratic values." World Development 32 (2): 329-341. DOI: https://doi.org/10.1016/j.worlddev.2003.08.005

Teusner, Annabel. 2016. "Insider research, validity issues, and the OHS professional: One person's journey." International Journal of Social Research Methodology $19 \quad$ (1): $\quad 85-96 . \quad$ DOI: https://doi.org/10.1080/13645579.2015.1019263

-----. 2019. Qualitative insider research. In SAGE Research Methods, edited by Paul Atkinson, Sara Delamont, Alexandru Cernat, Joseph W. Sakshaug and Richard A. Williams. Participatory and ArtsBased Research Series. DOI: http://dx.doi.org/10.4135/9781526421036845676

Vannini, Phillip and Jonathan Taggart. 2012. "Doing islandness: A non-representational approach to an island's sense of place." Cultural Geographies 20 (2): 225-242. DOI: https://doi.org/10.1177/14744744011428098

Warrington, Edward and David Milne. 2018. "Governance." In The Routledge Handbook of Island Studies: A World of Islands, edited by Godfrey Baldacchino. New York, New York: Routledge.

Wenene, Mary T., Trui Steen, and Mark R. Rutgers. 2015. "Civil servants' perspectives on the role of citizens in public service delivery in Uganda." International Review of Administrative Sciences 82 (1): $\quad 169-189 . \quad$ DOI: https://doi.org/10.1177/0020852315576704

$\mathrm{Wu}$, Xun, M. Ramesh, and Michael Howlett. 2015. "Policy capacity: A conceptual framework for understanding policy competences and capabilities." Policy and Society 34 (3-4): 165-171. DOI: https://doi.org/10.1016/j.polsoc.2015.09.001

------, M. Ramesh, and Michael Howlett. 2018. "Policy capacity: Conceptual framework and essential components." In Policy Capacity and Governance: Assessing Governmental Competences and Capabilities in Theory and Practice, edited by $\mathrm{Wu}$, Xun, M. Ramesh, and Michael Howlett. Cham, Switzerland: Palgrave Macmillan. 